\title{
DA CAVERNA À SALA ESCURA: O SONHO DE UM GESTO
}

\author{
Sandra Espinosa Almansa ${ }^{1}$ \\ Rosa Maria Bueno Fischer²
}

\begin{abstract}
RESUMO: Neste artigo, discutimos a questão da espectatorialidade, especialmente em relação à educação e ao tema da subjetividade. A partir da experiência cinematográfica do documentário A caverna dos sonhos esquecidos, de Werner Herzog, e dos estudos de Marie-José Mondzain a respeito do Homo spectator, o texto procura pensar, ensaisticamente, os modos pelos quais o olhar do espectador mobiliza consigo a criação do sujeito. Trata-se de propor um diálogo entre filosofia e cinema, problematizando a relação sujeito-espectador, neste presente em que vivemos e, sobretudo, no campo da educação.
\end{abstract}

Palavras-chave: Cinema. Espectador. Imagem. Educação.

\section{FROM THE CAVE TO THE DARK ROOM: THE DREAM OF A GESTURE}

\begin{abstract}
In this article, we discuss the issue of spectatoriality, especially in relation to education and the question of subjectivity. From the cinematic experience of Werner Herzog's documentary The Cave of the Forgotten Dreams, and Marie-José Mondzain's studies of the Homo spectator, the text aims to think, essayistically, the ways in which the gaze of the spectator mobilizes the creation of the subject. We propose a dialogue between philosophy and cinema, problematizing the subjectspectator relationship, in this present in which we live, and, above all, in the field of education.
\end{abstract}

Keywords: Cinema. Spectator. Image. Education.

\section{DE LA CUEVA A LA SALA OSCURA: EL SUEÑO DE UN GESTO}

RESUMEN: En este artículo, debatimos la cuestión de la espectatorialidad, especialmente en relación con la educación y al tema de la subjetividad. A partir de la experiencia cinematográfica del documental La cueva de los sueños olvidados,

Este artigo é oriundo do projeto Corpo Espectador e Formação Humana: da Textura da Cena ao Tecido do Mundo, financiado pelo Conselho Nacional de Desenvolvimento Científico e Tecnológico (CNPq). A pesquisa, realizada no período de estágio pós-doutoral de Sandra Espinosa Almansa (2018-2019), está vinculada ao projeto Manuscritos da Criação: As Artes e a Arte de Pesquisar em Educação, coordenado por Rosa Maria Bueno Fischer.

1.Universidade Federal do Rio Grande do Sul - Programa de Pós-graduação em Educação - Porto Alegre (RS), Brasil. E-mail: sandraealmansa@gmail.com

2.Universidade Federal do Rio Grande do Sul - Programa de Pós-graduação em Educação - Porto Alegre/RS, Brasil. E-mail: rosabfischer@gmail.com 
de Werner Herzog, y de los estudios de Marie-José Mondzain sobre el Homo spectator, el texto se invierte del ejercicio de pensar, ensayísticamente, los modos por los cuales la constitución del trabajo de la mirada del espectador moviliza juntamente con él la creación del sujeto. Se trata de proponer un diálogo entre filosofía y cine, problematizando la relación sujeto-espectador en este presente que vivimos y, sobre todo, en el campo de la educación.

Palabras-clave: Cine. Espectador. Imagen. Educación.

\section{Introdução}

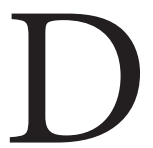

iante da criação do cineasta Werner Herzog (A caverna dos sonhos esquecidos), e do eco que a contemplação das imagens da caverna desperta, colocamo-nos a pensar, neste ensaio, sobre os modos pelos quais o trabalho do olhar espectador mobiliza consigo a criação do sujeito. Em outras palavras, desejamos problematizar, por meio da experiência cinematográfica propriamente dita, maneiras pelas quais seja possível à educação interrogar a relação sujeito-espectador, conferindo cuidadosa atenção à necessidade de fazê-lo, na atualidade. Trata-se de, em alguma medida, atualizar o que há de fundador e transformador, para nós, no gesto humano de ver e de dar a ver, de imaginar e de produzir imagens (MONDZAIN, 2015a).

O documentário rememora um tempo e um gesto. Muitos gestos. Domingo, 18 de dezembro de 1994. Três amigos se aventuram, no sul da França, a desbravar um território aparentemente inexplorado, nos penhascos rochosos, a poucos metros das margens do rio Ardèche. No alto das falésias, procuram por correntes de ar que emanam do solo, indicativas da presença de cavernas. O tempo escoa, mas a passagem das horas não desvanece a aventura. Todos se mantêm dispostos ao desconhecido até que, sob a luz atenuada do crepúsculo, uma pequena fenda na superfície dissemina o segredo da pedra, pondo-os diante de uma grandiosa aparição.

Em A caverna dos sonhos esquecidos (2011), Werner Herzog filma, com autorização do Ministério da Cultura da França, uma das maiores descobertas da história da cultura humana: a Caverna de Chauvet $^{1}$. Ao abrigo de uma enorme superfície pétrea, a cavidade de $400 \mathrm{~m}$ resguarda o mais antigo e já conhecido registro de arte pictórica rupestre, cujas inscrições inalteradas superam, numérica e secularmente, qualquer outra.

No âmago da gruta, as condições de filmagem (como é possível ver no documentário) são bastante limitadas: a equipe se reduz a quatro pessoas, a câmera inicial é uma pequena digital amadora e a luz utilizada se restringe a poucos painéis de luz fria, carregados junto ao corpo por cintos de baterias. No subsolo, apenas uma hora diária é permitida para a realização das tomadas. Em nada se pode tocar, tampouco é possível mover-se fora da plataforma metálica de $60 \mathrm{~cm}$, que conduz o percurso a ser seguido, e sobre a qual só é possível andar em fila. Às inscrições, ali deixadas por seres humanos há cerca de 32.000 anos, é claro, só é possível contemplar estando afastado.

Nada disso parece apequenar, no entanto, a experiência de ver-se próximo a tal distância. Nada parece conter o lampejo que possibilita ao espectador acolher, mesmo de longe, algo relativo ao humano, algo relativo a si mesmo. Entre os vestígios do olhar primevo, gravados na eternidade da rocha, e a fragilidade imprecisa das imagens fílmicas, insiste uma questão. Não relativamente a uma essência qualquer do cinema, senão a respeito do sujeito. Ou, especialmente, a respeito do posicionamento relacional da espectatorialidade e sua agência limiar na constituição e na transformação da subjetividade. 


\section{De um espectador a outro}

Da intimidade obscura onde adentra (pelo gesto de Herzog e sua equipe) a luz do cinema lançanos a possibilidade de olhar - em três dimensões, sem pressa e com algum milagre - os traços engenhosos deixados por seres humanos desaparecidos, nossos ancestrais, nas paredes de Chauvet. Silenciosa e escura, a sala de exibição, por instantes, investe-se da noite milenar que se empresta à tela. Tudo se passa como se, do limiar das imagens, aos olhos do espectador se desvelasse o nascimento de um olhar endereçado ao seu: como se, ao seu olhar, o primeiro espectador acenasse (MONDZAIN, 2015a).

Assim, de um universo familiar, mas distante, os pintores das cavernas parecem falar conosco. Os grandes pontos vermelhos, sinais feitos com a palma das próprias mãos e avistados originalmente tão logo se adentrasse o local, são ali deixados como para nos lembrar dos efeitos de uma intensa presença, em nossa relação com o mundo. Não obstante, diante desse passado feito de pedra e de imagens, uma pergunta se impõe: "Afinal, como saberíamos compreender tais marcas?"

No fascinante reduto filmicamente enquadrado diante de nós, os animais representados em diferentes situações, desenhados sobre protuberâncias rochosas, em posições e contextos que propõem dinamismo, são encontrados por toda a extensão da cavidade, exceto em sua arqueológica entrada: é quando a luz se exime que começam a surgir as primeiras imagens. Comprovada pelos resíduos fósseis de carvão vegetal, encontrados em vários pontos, a locomoção no interior da gruta era feita sob a luz de tochas, cuja dança incessante das chamas deu a ver ao ser humano a saída das figuras da pedra. Na medida em que movimentadas as tochas, os efeitos de luz e sombra aumentavam a ilusão de movimento, já sugerido nos desenhos, os quais, como repara a narração em over de Herzog, "deveriam parecer vivos e mover-se".

Sob a presença humana nas cavernas, o fogo era um acessório para a criação de variadas formas, sobretudo, zoomórficas. Servia para olhar as pinturas e, talvez, reunir as pessoas - algo como um ser social elementar, naquele contexto, convidando a uma experiência coletiva da imagem. Além disso, a claridade produzida pelo ser humano torna ali possível que ele mesmo venha, antropomorficamente, à luz, inscrevendo-se no visível com o próprio corpo, como nas marcas positivas ou negativas das mãos, que se encontram um pouco por toda parte.

Ao fazer a imagem surgir no seio da escuridão, o gesto ancestral, que funda a possibilidade de uma relação imaginária e do olhar com um mundo visível, afirma já a condição limiar, imediata à espectatorialidade humana. Somos convidados a reparar, justo na origem 2 do exercício de ver e de dar a ver as coisas, o quanto é preciso que algo escape à luminosidade evidente para que seja possível ver e fazer ver, seja a visão do mundo, seja a possibilidade do sujeito de ver a si próprio (MONDZAIN, 2015a).

Ao deixar atrás de si imagens de sua autoria, "para que delas pudéssemos recolher algo relativo à nossa própria definição", o primeiro espectador, tal como propõe Marie-José Mondzain (2015a p. 16) no belíssimo ensaio "Homo spectator: Ver, fazer ver", é também ele "um sujeito nascente", o ponto de partida da humanidade. É ele o homem descoberto pela paleontologia, justamente no momento em que dá início a um mundo no qual se distancia de sua animalidade constitutiva, quando se faz ver, ao dar a ver aquilo que quis mostrar. Das mãos do que foi o primeiro espectador, a filósofa recolhe "a capacidade de falar e de dizer hoje que gestos fizeram nascer juntos o homem e a imagem e os desafios associados" (MONDZAIN, 2015a, p. 29). Trata-se de um homem que entra na história que ele próprio pode narrar, partilhar - o que nos convida a pensar profundamente a respeito do espectador que hoje nos tornamos. Interrogamo-nos sobre como se constitui nosso olhar e, com ele, como se dá nossa presença no mundo, nossa aparição ou aniquilamento subjetivo, numa realidade plural, diante da infinidade de coisas que há para ver em nosso próprio tempo. 


\section{Olhos que se abrem para o mundo}

No relato imaginado por Mondzain, um sinal nos é dirigido das inscrições gráficas do ser humano nas paredes paleolíticas. O que ele transmite, porém, é menos da ordem da decifração do que da esfinge, na medida em que a possibilidade de ver, por sua vez investida da opacidade da noite, liga-se nessa relação à impossibilidade fundadora do sujeito de ver a si próprio. Avistado o aceno, a autora propõe interrogar as imagens, não na qualidade de objetos da visão, mas como surgidas "de um gesto que funda a condição de possibilidade de uma relação, a do nosso olhar com um mundo visível” (MONDZAIN, 2015a, p. 29). O sentido desse gesto diz-nos alguma coisa hoje, porque diz coisas sobre nós.

Importa reter, aqui, sobretudo, o relançamento da questão do visível e das imagens, em direção ao que compete ao espectador, como causa e efeito de si, do que vê e do que dá a ver. Trata-se de uma tentativa de contribuir para a ampliação do debate a respeito da problemática educacional de um regime de subjetividade das imagens, em que a constituição do sujeito-espectador se modula, inclusive, no exercício dessa troca entre olhar o mundo e dar a ver a outros os mundos que ele vê. A indagação insistente é: "Como se organiza a constituição subjetiva do sujeito, relativamente às operações e experimentações imagéticas e imaginárias nas quais ele se envolve?"

Imóvel na poltrona, diante das imagens do filme de Herzog, o espectador transita pela gruta. Junto ao cineasta, participa intensivamente da vida partilhada das imagens, reunido ao espetáculo fantasmagórico das formas que aparecem e desaparecem, agora, mediante as luzes do cinema. De que maneiras, pois, o que vemos e o que nos olha nos instigam a pensar o legado dessas práticas milenares de criação e contemplação de imagens, a partir de uma modalidade de experiência que ainda hoje nos afeta - a experiência cinematográfica? E mais importante: como a educação pode se ver aí implicada?

As pinturas e desenhos descobertos em Chauvet nos lembram da imanência de um corpo a corpo - o corpo humano e a parede do mundo, entre os quais se disputa, mediante a operação de distanciamento e aproximação, o sentido dos gestos por vir (MONDZAIN, 2015a. Sugerem-nos, ainda, quão longevo se exerce o fascínio da imagem cinética sobre o ser humano, assim como nos recordam da sinestesia constitutiva da aventura do olhar. Ali, a depender do deslocamento do espectador, os animais representados parecem se mover, ora virando-se de uma posição a outra, ora dando passos. Entre as figuras parietais e o corpo espectador, as variações de sombra e luz induzem efeitos cinéticos rudimentares, sugerindo uma presença ancestral, no espírito paleolítico das cavernas, de uma forma de protocinema - expressão utilizada por Herzog no documentário.

Dada a expressividade proximal, salvo o enorme arcaísmo que a limita, com o princípio básico que viria a caracterizar o dispositivo cinematográfico (a decomposição do movimento em instantes isolados e a reconstituição desse movimento por meio da projeção luminosa), a percepção visual das figuras paleolíticas nas cavernas, com seus cortes, sobreposições e variação luminosa, parece envolver uma relação entre tempo e movimento, mais cinematográfica do que propriamente pictórica (WACHTEL, 1993). Tudo se passa como se, embora tivessem mãos e ferramentas de pintores, os artistas das cavernas portassem os olhos e a mente do cineasta e fizessem já uma espécie de "cinema underground" (WACHTEL, 1993, p. 140). De mais a mais, seria preciso especialmente notar de que modos ali se inaugura um tempo distinto da passagem das horas, das tarefas cotidianas, da duração do viver - um tempo singular, "para olhar a vida e para pensá-la" (MONDZAIN, 2015a, p. 33).

Ainda que não se pretenda imergir profundamente no escorregadio terreno da discussão sobre as origens do cinema, o que exigiria um estudo bem mais extenso e profundo do que este texto comporta, talvez seja forçoso contorná-lo parcialmente. Em primeiro lugar porque se parte de que a ideia do cinema, 
por efeito de uma vontade milenar, é seguida de perto ao longo da história humana, de seu pensamento e de suas formas de expressão (MACHADO a, 1997). Apesar das controvérsias em torno da questão, alguns autores defendem que tal ideia se faz presente, no decurso de uma longa demanda imaginária e desejante do pensamento humano, desde as manifestações artísticas da pré-história e o pensamento filosófico antigo, em Platão e Lucrécio. É possível também localizá-la em diferentes estudos e invenções técnicas, datados desde meados do século X até o século XIX, atualizando-se quando da realização do processo cinematográfico propriamente dito.

Bastante polêmica, a questão sobre as "origens" do cinema e das linhagens incertas às quais ele se liga incita intermináveis discussões. Mesmo os mais respeitados estudiosos se enredam nos labirintos desse começo. De acordo com Machado (1997), a tentativa dos historiadores de descortinar o primeiro ancestral do cinema remete-os cada vez mais para trás, até os mitos e ritos dos primórdios, indicando não consensual e arbitrária a eleição de marcos cronológicos inaugurais. Seja como for, o que emerge como um pormenor bastante importante, em meio a toda essa consideração sobre o passado, é algo reprimido na história do cinema. Machado (1997) observa que as histórias do cinema falam, basicamente, de sua positividade técnica, ou das teorias científicas da percepção e dos aparelhos destinados a realizar a análise e a síntese do movimento. Com isso, o autor constata que elas acabam por reprimir, em seu discurso, o que também a sociedade reprimiu na própria história do cinema; isto é, aquilo que constitui o motor mesmo do movimento invisível que a ele conduz.

De nossa parte, o reconhecimento dessa lacuna não objetiva absolutamente uma escavação do passado, com vistas a identificar, simplesmente, uma cena originária referente ao cinema ou à imagem cinematográfica. Se aqui tomamos como ponto de partida as imagens de Chauvet, é antes ao modo de uma ruptura, cujo gesto fundador indica, ao mesmo tempo, um lugar de proveniência do homem e sua indeterminada destinação (MONDZAIN, 2015b). Ora, da presença germinativa da ideia de cinema como movimento invisível de sonho e devir, fantasmagoria e imaginário, teríamos perdido para sempre a voz? Como sobreviveram e sobrevivem seus quaisquer efeitos na língua, em nosso estado de espectadores, com o qual constituímos quem somos?

Dos cortes imóveis das cavernas, que conferiam às imagens, por efeito de variações luminosas, a ilusão de movimento, aos cortes móveis da imagem cinematográfica e além, tem sido interminável o trabalho humano de um fazer ver, por imagens em movimento. Relativamente à genealogia mesma do cinema, Laurent Mannoni (2003) faz um exaustivo inventário dos aparelhos que, desde o século XIII, constituem parte dos esforços do ser humano, pelo domínio da óptica e da química e sua aplicação na criação e na captura de imagens. Parte desse trabalho de criação e projeção artesanal de imagens pode ser observada também no documentário O filme antes do filme (1986), de Werner Nekes. Nele, Nekes dá a ver um sem número de invenções, entre brinquedos ópticos e artefatos, dos mais simples aos mais sofisticados, e sugere que o cinema é o produto final de vários inventos, inicialmente associados às misteriosas artes da magia e da alquimia. Ainda que não consideremos o cinema como produto final de uma história forçosamente não linear e descontínua, marcada por enorme diversidade de tentativas, para lograr movimento às imagens, seria preciso chamar a atenção para a riqueza imaginária que rodeia a pré-história de sua invenção, muitas vezes restrita aos começos instituídos e legitimados por certo modo de fazer história.

Desde que as rápidas e significativas transformações do século XIX possibilitaram a realização e a difusão do processo cinematográfico, grande parte do que é dito sobre ele, em detrimento de outras posições, arrola exemplos e minúcias acerca de seu desenvolvimento técnico. Herdeira de uma cultura racionalista, adepta dos ideais de progresso que movimentavam o desenvolvimento urbano, a expansão industrial e a classe média, bem como a aceleração dos meios de transporte e também dos meios de comunicação, não 
é de estranhar que a história oficial do cinema tenha sido construída sob a supremacia de um discurso científico, acentuadamente positivista, em meio ao qual o cinema nascia. A posição de destaque conferida a homens de ciência e sua contribuição técnica, ainda que por vezes indireta, no desenvolvimento do aparelho cinematográfico, sobrepôs-se, assim, à disparidade de invenções e intenções de ilusionistas, bricoleurs e curiosos. Envolvidos com diferentes modalidades de espetáculo da época e alheios ao interesse dos homens de ciência em tornar mensurável o gesto humano por meio da análise do movimento, esses últimos, mais interessados na síntese efetuada pelo projetor, possibilitaram a realização do cinema como uma modalidade "capaz de penetrar fundo na alma do espectador, mexer com seus fantasmas e interpelá-lo como sujeito" (MACHADO, 1997, p. 18).

É claro que, se voltarmos os olhos para tão longe, na direção das imagens rupestres, não é possível enxergar com nitidez formas e operações cinematográficas, tais como as que viemos conhecendo desde a constituição mesma do cinema, dadas suas condições determinantes. Como pontuamos anteriormente, não se trata aqui de buscar um reconhecimento dessa natureza. Sejam quais forem as distâncias que separam as diferenças técnicas dos espetáculos luminosos que antecedem ou que integram finalmente o cinema, importaria neles avistar algo como o predomínio de uma vontade que busca "recriar a vida, ver um alter ego do ser humano [...] animar-se" (MANONNI, 2003, p. 28).

O exercício de teorização que fazemos aqui excede, propositadamente, as fronteiras da história do cinema. Logo, tomamos em conta dois momentos distintos - o da expressão rupestre das cavernas, no amanhecer da humanidade, e o de uma experiência moderna e contemporânea do cinema -, e propomos que ambos se comuniquem como momentos distintos da história de um sonho. Ou seja, o sonho de apreender a realidade, de transgredir o real e guardar a vida em imagens duradouras. É a partir desse diálogo que estas linhas se propõem a pensar a respeito do sonho de um gesto, o gesto de um corpo espectador, criador e contemplador de signos, e sua relação inelutável de alteridade, aqui compreendida (e colocada) como problema crucial à educação, na medida em que tal problematização faz espraiar a questão do espectador da ordem da estética e a aviva naquelas da ética e da política.

De que maneiras o aceno das imagens rupestres nos convida a pensar a respeito da experiência do cinema e dos modos pelos quais podemos hoje nos constituir como sujeitos por vias imagéticas? Seria preciso presumir que elas acenam, com a força infalível de seu efeito, para nossa presença no mundo, mas também para o legado de nossa ausência. A expansão do conceito de cinema a que aludimos, pois, encontra, de algum modo, sua obscura e luminosa singularidade na constituição humana, mesmo antes que a humanidade pudesse ter encontrado o seu estado documentado no lugar único em o cinema propriamente dito se tornou mesmo na ficção (MONDZAIN, 2015a).

\section{O devir de um sonho}

Fosse duplicando o mundo visível (como fizeram os precursores filmes dos irmãos Lumière), fosse por meio da evasão para o onírico (como nos filmes de Georges Méliès), o mundo via nascer, no cinema, ao fim do século XIX, um novo universo, que se abria ao sonho de seus olhos. Nos Estados Unidos e na Europa, novos sistemas de circulação e trabalho criavam novas relações, as quais impeliam outros modos de vida, sociais, culturais e políticos. Diante de um mundo que combinava outras velocidades, a transformação industrial e seu sistema de fábricas, para além de regular os sujeitos, suas tarefas e seus gestos, transformava, igualmente e com a mesma rapidez, os objetos à vista das pessoas. Em meio a tantas transformações, uma mudança substancial ocorria nos modos de ver e de ser visto. 
Ao passo que se transformava sobremaneira o exercício de viver a vida, também a vida se transportava para a tela, e aquela nesta se imiscuía. Rebento de uma época que perdia definitivamente o domínio e a desenvoltura de seus gestos, o cinema atraía as massas à sala escura, porque as fazia ver nele uma possibilidade de criação (AGAMBEN, 2008). Ao mesmo tempo em que possibilita a uma sociedade registrar tal perda, é no cinema (então, mudo) que se procurará, de modo mais exemplar, resgatar esses gestos e evocar aquilo que estava escapando para sempre das mãos. No entanto, pode-se perguntar: "O que é, afinal, o gesto?"

Seguindo uma indicação antes observada por Varrão, Agamben (2008, p. 12) retoma a compreensão de que o gesto se inscreve na esfera da ação, como distinto do agir e do fazer: o que o caracteriza é que, nele, "não se produz, nem se age, mas se assume e suporta”. Assumir uma ação ou suportá-la, nesse sentido, leva à identificação do gesto como um gênero da ação que rompe com a distinção aristotélica entre o gênero do agir (da práxis) e o do fazer (da poiesis). Isso porque, diferentemente da práxis (que tem seu fim em si mesma) e da poiesis (cuja finalidade é outra que o próprio fazer), o gesto não é nem um fim sem meios nem um meio em vista de um fim. Como "exibição de uma medialidade", o gesto "faz aparecer o ser-num-meio do homem, abre para ele a dimensão ética" (AGAMBEN, 2008, p. 13). Não sendo, em absoluto, um elemento não linguístico, o que está em questão no gesto não é tanto um conteúdo pré-linguístico, mas “a outra face da linguagem, o mutismo inerente ao próprio ser falante do homem, o fato de este morar, sem palavras, na língua” (AGAMBEN, 2015, p. 212). Relacionado intimamente à linguagem como força operante mais antiga que a expressão conceitual, o gesto diz respeito ao ethos, concerne à esfera da ética - a qual ele abre como esfera mais própria do ser humano - e à dimensão política - esfera da integral gestualidade dos seres humanos. Ética, escreve Agamben, "não é a vida que simplesmente se submete à lei moral, mas a que aceita, irrevogavelmente e sem reservas, pôr-se em jogo nos seus gestos" (2007, p. 61).

Poder-se-ia inferir, no fazer ver das inscrições rupestres, uma espécie de desadaptação soberana da natureza do gesto. Ao desviar o corpo e os gestos das tarefas cotidianas de sobrevivência e conservação, o ser humano não apenas faz mudar a função e o fim da boca e das mãos como também instaura uma nova temporalidade. O nascimento do Homo spectator, escreve Mondzain (2015a, p. 33), "é uma insurreição do nascimento do sujeito imagético", com cujo gesto o homem nasce para sua própria vida, ao transformar, por meio de uma relação imaginária, a relação de forças que mantém com o real. O que esse gesto inaugural guarda, no entanto, o que o excede e nos é enviado (sem que dele se dispense uma perda da adaptação a uma forma de vida) é o que do gesto permanece inexpresso: o vazio que se instala em cada ato de expressão, na mesma medida em que ela é possível (AGAMBEN, 2007). O que nos chega desse buraco que nos é endereçado ao olhar, ao mesmo tempo como testemunho e convite, é o vazio como lugar possível de uma forma de vida.

Ali, entre o corpo humano e a parede do mundo, o gesto trata da criação do homem à imagem da sua própria mão. À diferença de propor um objeto à sua visão, o homem da caverna põe-se no mundo como espectador, e seu gesto, na marca da mão, "dá a ver o plano de aparição da diferença como inseparável dos signos que constituem a presença de um sujeito face ao mundo" (MONDZAIN, 2015a, p. 44). Nesse gesto, que faz nascerem juntos o homem e a imagem, o sujeito-espectador não existe nem pode ser alcançado substancialmente; ele é, antes, posto no trajeto móvel das trocas de signos, palavras e imagens; ele é resultado do encontro e do corpo a corpo com os dispositivos em que foi posto. Nesse sentido, tal como escreve Agamben, talvez a história dos homens "não seja nada mais do que um incessante corpo a corpo com os dispositivos que eles mesmos produziram” (2007, p. 63).

Ao operar no visível um gesto imagético, o cinema "reconduz as imagens para a pátria do gesto", faz dele seu elemento: "o cinema é o sonho de um gesto" (AGAMBEN, 2008, p. 12). Vale rememorar 
que, no momento de profundas transformações, em que a aurora do cinema se preparava, já não era possível manter, ao custo de uma "crise da psicologia", a posição que consistia em colocar as imagens na consciência, como realidade psíquica, e os movimentos no espaço, como realidade física (DELEUZE, 1985). O cinema forneceria a própria evidência de uma imagem-movimento, na qual o gesto não se reduz à expressão de uma interioridade, nem à ação que conduz a uma conclusão narrativa. A análise de Deleuze, no entender de Agamben (2008), deve ser estendida ao estatuto mesmo da imagem na modernidade, quando sua rigidez teria sido despedaçada. Animadas por uma polaridade antinômica que, de um lado, faz delas a reificação isolada de um gesto, e do outro, conserva-lhes intacta a dynamis que as envia sempre para além de si mesmas, as imagens podem ser vistas como "fragmentos de um gesto ou de fotogramas de um filme perdido" (AGAMBEN, 2015).

Nessa perspectiva, a tarefa do diretor de cinema seria "introduzir nesse sonho o elemento do despertar" (AGAMBEN, 2015, p. 12). Deve-se desconfiar, entretanto, que, numa tal tarefa, o elemento do despertar se limite unicamente ao visível. É preciso não esquecer o duplo registro da imagem (visibilidade/invisibilidade), tampouco sua duplicidade inerente (interioridade/exterioridade). Uma vez dentro da caverna, diante da imagem, na pátria do gesto, qualquer amanhecer a indicar a saída jamais será imperturbável. Assim como o fazer ver das inscrições paleolíticas se destaca "numa autonomia plena, separado de qualquer querer dizer" (MONDZAIN, 2015a, p. 32), a produção e a exegese dos sentidos da imagem não poderiam ser reduzidas ao significado de um objeto.

Em outras palavras, deve-se marcar um movimento compreensivo que desloca o espectador do imediatamente visível e persegue sempre o inacabável do gesto. Diante das imagens rupestres, não interrogaram os antropólogos, incessantemente, sobre sua expressão ritual, religiosa, xamânica, sexual? Julien Monney, o arqueólogo-espectador exposto à intensidade obscura da gruta, cuja emoção fez povoar os sonhos de leões por noites a fio, dirá a Werner Herzog que são oblíquos os modos de compreender as imagens de Chauvet. É preciso tempo, certa atenção e descanso para absorver algo da força animalesca, em todo caso, poderosa e profunda dos signos. Para compreender a caverna, é preciso um movimento de aproximação e distanciamento. É necessário silêncio e um certo aquietar-se, como na bela sequência em que vemos Jean Clottes pedir à equipe de pesquisadores, dentro do quadro, que não se mexa e silencie, para ouvir o silêncio da gruta. Quem sabe assim, confiam eles, cada um poderá escutar, também, as batidas do próprio coração.

Seja abandonado ao fundo escuro da caverna, onde, por força da tocha acesa por suas próprias mãos, o ser humano vê, faz ver e se ilumina, seja atraído à sala escura do cinema, o espectador penetra um lugar onde alguma coisa nasce, sobrevive e se transforma. Um espaço no qual o encontro com o fora não prescinde absolutamente de um mergulho na interioridade, nem de um vir a ser no mundo. Ao evocar "o cenário que instaura simultaneamente a impossibilidade de se ver, o nascimento da imagem como operação de retração, a identificação de si na dessemelhança e a necessidade do apoio do mundo para existir fora dele", Mondzain (2015a, p. 35) nos diz, sobre o estado de espectador, de sua relação inaugural de alteridade, da ligação do homem com o fora de si, para poder lançar um olhar de volta a si. À diferença do que ocorre na caverna platônica, de cujas trevas só se pode sair, para aceder à iluminação da verdade, por meio de uma luz exterior que nada deve ao sujeito em si mesmo, no relato imaginado pela filósofa, "o homem da gruta fabrica o seu horizonte e faz-se nascer ao estender a mão em direção a uma alteridade irredutível e vivificante, a sua” (MONDZAIN, 2015a, p. 41). O gesto humano que faz surgir o olhar do mundo sobre si é, nesse sentido, um gesto político, instaurador da tensão ininterrupta que faz do ser humano, ao mesmo tempo, o objeto da visão e o sujeito de um olhar, no mundo que inicia. 


\section{Gesto imagético e criação do sujeito}

Da hipótese abrangente de que a experiência do cinema se dispõe a serviço da educação, interrogamos a questão do espectador, mediante a suspeita de que, numa contextura hodierna, os processos de subjetivação aí implicados conjurem forças que movimentem o domínio da criação do sujeito. A partir do ideário com que se produz este texto, entende-se que o espectador ocupa uma posição crucial no tocante a problemas de ordem estética, mas exerce também um papel essencial quanto a temas de caráter ético e político. $\mathrm{O}$ reconhecimento do diagnóstico elementar, de que "nada e ninguém existe neste mundo cujo próprio ser não pressuponha um espectador" (ARENDT, 2012, p. 35), demanda assentirmos sua centralidade, igualmente, na chave do significado dos assuntos humanos.

Historicamente situada no cerne das discussões entre arte e política, a questão do espectador é também um dos grandes temas da teoria do cinema, em que tem sido reiterada e reelaborada ao longo do tempo, ainda que com objetivos variados e à diferença das linhagens teóricas adotadas. A interrogação a respeito do que acontece na experiência audiovisual cinematográfica foi posta, desde sua origem, ao lado do esforço de demonstrar as afinidades imediatas entre a estrutura do filme e as estruturas próprias ao campo da subjetividade (XAVIER, 1983).

Desse vínculo, que atravessa sem jamais esgotar o pensamento do cinema, buscamos nos aproximar, chamando à vista uma dimensão específica, relativamente à educação e ao problema da possibilidade da criação do sujeito por vias das operações imagéticas. Ora, por que razão, a nosso ver, é urgente que se considere, na educação, o que acontece ao espectador? Considerar a dimensão do papel da imagem na construção subjetiva, nesse sentido, consiste em "tomar conta daquilo que faz de um sujeito que olha um sujeito da cultura, isto é, um sujeito reconhecido na sua presença, ao mesmo tempo singular e política" (MONDZAIN, 2015a, p. 152), cujos gesto e palavra, de certa maneira, não prescindem do olhar.

À semelhança do primeiro espectador, o espectador de cinema, aqui problematizado, "transforma por alguns instantes ou algumas horas a temporalidade do seu corpo, por via de um gesto cinematográfico" (MONDZAIN, 2015a, p. 275). Saindo de si e abrindo-se à temporalidade própria do jogo que o interpela, pode finalmente "aceder a si mesmo não como um conjunto de dados predeterminados, mas como o processo mesmo de abertura para o jogo do mundo" (LUZ, 1994, p. 5). À semelhança do homem desembaraçado da caverna, cujo espaço do olhar é o de uma deslocação contínua entre claridade e escuridão, o espectador é um sujeito descentrado, um sítio móvel, cujo lugar não pode ser firmado. Ainda que imóvel, ele é mobilizado por diferentes afetos na fruição fílmica - a qual se tece intimamente relacionada a seu corpo e sentidos - e exposto à vida que lhe podem dar as imagens, justamente na medida em que tomam parte na composição de seus gestos constituintes. Desse modo, desprendido de uma ordem meramente contemplativa, o espectador se torna "sítio político de um gesto, onde o contato se opera na partilha dos olhares" (MONDZAIN, 2015a, p. 276). Diante dos filmes, a subjetividade, sempre processual, é profusamente convocada à diferença, a modos de sensibilidade, modos de relação com o outro, de relação consigo; nesse sentido, com efeito, a constituição do sujeito se vê problematicamente ocupada da questão do espectador. Nas palavras de Mondzain (2015a, p. 74), “a imagem pode dar vida quando o nascimento do espectador é o nascimento do sujeito".

Ao nos colocarmos à espreita das imagens, corremos o risco de sermos, em alguma medida, capturados por elas. À semelhança de Herzog e sua equipe, em A caverna dos sonhos esquecidos, que, em busca de imagens, não tiveram como esconder-se para ficar fora do enquadramento, o espectador participa da imagem, na medida em que por ela se desloca, em que se entrega ao percurso muitas vezes íngreme, estreito, sinuoso e escuro que o leva até ela. Em que pese ao espectador estar a salvo da interioridade da orquestração da produção imagética, sendo capaz de dispensar os "talabartes de ancoragem”, utilizados pelos 
cineastas para deslizar com segurança pelos caminhos da imagem, ele não poderia em tempo nenhum estar a salvo de seus efeitos, ao passo que a si mesmo cabe, em alguma medida, ser-lhe o exterior. Como a educação medeia, então, a estrada que nos leva a esses lugares subsolares? Como se afirma nesses lugares sensíveis, onde compartilhamos a história de nossa própria humanidade?

De início, talvez se trate de confiar que os caminhos que levam às imagens, como os caminhos que levam a si mesmo, as veredas do gesto, estão sempre por se fazer. A educação, entendida como formação humana ou como formação cultural, está sempre em processo e, nesse processo, sem dúvida, tem parte importante o papel da imagem na constituição subjetiva. A humanidade, nesse sentido, já não se ajusta ao significado de uma paideia como forma acabada ou ideal do homem, o que não exclui a infinda busca por uma condição de maior perfeição em nosso modo de ser humano (SEVERINO, 2006). A respeito disso, se olharmos para a cinematografia de Herzog, por exemplo, já no início, filmes ficcionais como Também os anões começaram pequenos (1970), Aguirre, a cólera dos Deuses (1972), O enigma de Kaspar Hauser (1974) e Woyzek (1979) - todos nos quais a gestualidade dispõe-se diferentemente -, lembram à alma humana, cada um a seu modo, que a humanidade não é uma aquisição definitiva, substancialmente segura, nem uma consequência lógica de nossa condição. Documentários como Lições da escuridão (1992), Ao abismo (2010) e Eis os delírios do mundo conectado (2016) nos lembrarão, até as últimas consequências, que a humanidade "está em nossas mãos e sempre por se fazer" (MONDZAIN, 2015a, p. 89) - como, de outro modo, já nos alertavam, silenciosamente, as mãos paleolíticas.

Embora tenha sempre alternado filmes de ficção e documentários, Herzog dispensa enfática e deliberadamente a fronteira entre ficção e documentário, em favor da categoria indistinta "filmes". As relações indissociáveis entre o ser humano e a natureza e entre natureza e cultura, insistentes ao longo de sua obra, podem ser vistas, de modo gestualmente diverso, nas filmagens realizadas pelo diretor ao redor de todos os continentes do mundo. $\mathrm{O}$ trabalho com seres humanos interessa-lhe, justamente, na medida em que torna possível explorar cinematograficamente a condição humana, num momento particular e num ambiente específico, nas situações-limite, desafios a enfrentar e obstáculos a transpor. Rodados em décadas e territórios distintos, com temas variados e pontuais, os filmes de Herzog constituem exemplos tão diferentes quanto competentes, a retratar seja a singularidade do gesto humano (sua dimensão ética e sua participação política, na maneira como se organizam diferentes grupos culturais), seja a universalidade do humano (para além das fronteiras que, de um modo ou outro, distinguem-nos). Pode-se dizer que A caverna dos sonhos esquecidos se inscreve paradigmaticamente entre ambos os sentidos. Se, por um lado, não resta dúvida de que suas imagens refletem algo de nossa civilização, por outro não deixam de também dizer respeito ao que temos de mais íntimo. O que, em um só golpe, atende a uma urgência autoral do realizador, na busca e na obtenção das imagens de seu cinema, e torna possível a mobilização de intensidades de nossas próprias trajetórias.

À semelhança de nossos antepassados, é ainda sob alguma luminosidade que nos colocamos diante da entrada, na caverna onde se guardam as imagens. Contudo, como eles, não estamos incólumes a derrocadas quaisquer que se interponham diante de nós e nos impeçam de acessar o interior, ver livremente o que ali há para ver. Ou a avalanches que, de dentro, só nos permitam ver dali fragmentos, impedindo-nos a vista de uma abertura maior. À semelhança de Herzog e sua equipe, não é subindo e descendo escadas, em movimentos correspondentes, que chegamos de todo modo às imagens ou que delas "saímos". É antes fazendo voltas, nos arrastando, ficando às vezes comprimidos, turvos, ora ao longe, ora aproximando-nos, no limite, afinal, de nosso próprio corpo, nos limiares de nossos gestos. Essa não passividade do espectador o conduz a explorar, afetiva e imaginariamente, os percursos possíveis que se abrem diante/dentro de um universo imagético.

Ora, numa época em que reinam os dispositivos da identificação e do terror e se arruínam as possibilidades de alteridade, bem como a energia constituinte do próprio estatuto do espectador, face à cultura 
de massa e da indústria do espetáculo (MONDZAIN, 2015a), o risco de aniquilamento do espectador cresce justo na direção oposta de sua liberdade. Assim, em matéria de educação, é fundamental operar na afirmação dessa liberdade, com que imaginamos ser possível ao espectador apossar-se de sua própria aparição subjetiva relativamente ao que vê, de modo a perceber e problematizar criticamente a si mesmo (e ao que aceita, recusa ou transforma), em meio a operações reais e imaginárias, no campo cruzado das imagens e dos olhares com que se envolve.

Preocupar-se educacionalmente com a questão do espectador, portanto, significa dar a devida importância à sua participação inarredável nos diferentes modos de produção e recepção semiótica, os quais se correlacionam necessariamente com sua presença no mundo e com o legado de uma ausência. Trata-se de conferir atenção e cuidado à imanência das trocas entre o olhar e a língua, entre o olhar e os gestos de um corpo, entre os recursos desse espectador e as marcas que deixa no mundo. Ocupar-se educacionalmente dessa questão é crucial, sobretudo porque, no limite de o verbo ver se tornar um infinitivo sem sujeito, é a barbárie que ameaça um mundo sem espectador (MONDZAIN, 2015a).

No final do documentário, o plano fixo da imagem negativa de uma mão, impressa na quietude da pedra, lembra-nos de algo relativo a nosso nascimento para a humanidade, do gesto humano de autofundação de si por si, como "a figura de um apelo ao reconhecimento do que faz de nós humanos e que temos em nossas mãos" (MONDZAIN, 2015a, p. 51). Talvez o trabalho da educação por uma sensibilidade estética, no duplo registro com o cinema, permita realizar agenciamentos que funcionem no próprio coração dos indivíduos, produzindo variações que digam respeito à percepção, ao sensível, à memória, às relações com o outro, à relação consigo, com o ambiente físico e cultural; enfim, questões que digam respeito a uma ética, a uma forma de vida e suas transformações. Porque, se o compromisso da educação é com a desbarbarização (SEVERINO, 2006), é em favor de um devir humanizador que insistimos na articulação filosófica entre educação e cinema, cujo exercício se empenha na construção de novos modos de subjetividade e de um gesto novo, como novidade e como diferença.

\section{Notas}

1. Após Pierre-Oscar Lévy ter realizado o documentário Dans le silence de la grotte Chauvet, rodado entre 1999 e 2003 , Werner Herzog foi autorizado (graças, igualmente, a uma rara anuência governamental) a realizar filmagens no interior da caverna localizada na comuna francesa Vallon-Pont-d'Arc. Sob um grande penhasco de calcário rochoso que margeia o antigo leito do rio Ardèche, Chauvet-Pont-d’Arc presta homenagem ao espeleólogo Jean-Marie Chauvet, líder do grupo exploratório do qual participavam também Éliette Brunel e Christian Hillaire.

2. Essa origem seria preciso entendê-la no sentido de paradigma histórico, tal como Didi-Huberman sugere, ao invocar Walter Benjamin: "nem ideia nem fonte - mas um turbilhão no rio" (1998, p. 171, grifos do autor). Ou seja, origem como "uma espécie de formação crítica que, por um lado, perturba o curso normal do rio [...] e, por outro lado, faz ressurgir corpos esquecidos pelo rio", corpos aos quais "ela 'restitui', faz aparecer, torna visíveis de repente, mas momentaneamente: eis aí seu aspecto de choque e de formação, seu poder de morfogênese e de 'novidade' sempre inacabada, sempre aberta" (DIDI-HUBERMAN, 1998, p. 171, grifos do autor).

\section{Referências}

AGAMBEN, G. Kommerell, ou do gesto. A potência do pensamento: Ensaios e conferências (2005). Belo Horizonte: Autêntica, 2015, p. 211-221.

AGAMBEN, G. Notas sobre o gesto. Artefilosofia (1996). Ouro Preto, n. 4, p. 09-14, jan. 2008. 
AGAmbEN, G. O autor como gesto. Profanações (2005). São Paulo: Boitempo, 2007, p. 55-64.

ARENDT, H. A vida do espírito: O pensar, o querer, o julgar (1971-1978). Rio de Janeiro: Civilização Brasileira, 2012.

DELEUZE, G. A imagem-movimento (1983). São Paulo: Brasiliense, 1985.

DIDI-HUBERMAN, G. O que vemos, o que nos olha (1992). São Paulo: Ed. 34, 1998.

LUZ, R. A experiência do espectador comum de cinema. Cinema. Rio de Janeiro: Jorge Zahar, v. 1, n. 1, 1994, p. 3-8.

MACHADO, A. Pré-cinemas e pós-cinemas. Campinas: Papirus, 1997.

MANNONI, L. A grande arte da luz e da sombra: Arqueologia do cinema (1995). São Paulo: Editora SENAC/ UNESP, 2003.

MONDZAIN, M.-J. Homo spectator: Ver, fazer ver (2007). Trad. Luís Lima. Lisboa: Orfeu Negro, 2015a.

MONDZAIN, M.-J. A imagem entre proveniência e destinação. In: ALLOA, E. (org.). Pensar a imagem. Belo Horizonte: Autêntica, 2015b, p. 39-53.

SEVERINO, A. J. A busca do sentido da formação humana: Tarefa da Filosofia da Educação. In: Educação e Pesquisa, v. 32, n. 3, São Paulo, set.-dez. 2006, p. 619-634.

WACHTEL, E. The First Picture Show: Cinematic aspects of cave art. Leonardo, San Francisco, v. 26, n. 2, 1993. XAVIER, I. (org.). A experiência do cinema: Antologia. Rio de Janeiro: Edições Graal/Embrafilme, 1983.

\section{Filmografia}

A CAVERNA dos sonhos esquecidos [Cave of Forgotten Dreams]. Direção: Werner Herzog. Canadá/EUA/ França/Alemanha/UK, 2011 (90 min).

AGUIRRE, a cólera dos Deuses [Aguirre, der Zorn Gottes]. Direção: Werner Herzog. Alemanha, 1972 (95 min). AO ABISMO [Into the Abyss]. Direção: Werner Herzog. EUA/UK/Alemanha, 2010 (107 min).

EIS OS DELÍRIOS do mundo conectado. [Lo and Behold: Reveries of the connected world]. Direção: Werner Herzog. EUA, 2016 (98 min).

LIÇÕES da escuridão. [Lektionen in Finsternis]. Direção: Werner Herzog. França/UK/Alemanha, 1992 (54 min).

O ENIGMA de Kaspar Hauser [Jeder für sich und Gott gegen alle]. Direção: Werner Herzog. Alemanha, 1974 (110 min).

O FILME antes do filme [Was geschah wirklich zwischen den Bildern?]. Direção: Werner Nekes. Alemanha, 1986 (83 $\mathrm{min})$.

TAMBÉM os anões começaram pequenos [Auch Zwerge haben klein angefangen]. Direção: Werner Herzog. Alemanha, 1970 (96 min).

WOYZEK. Direção: Werner Herzog. Alemanha, 1979 (80 min) 


\section{Sobre as Autoras}

Sandra Espinosa Almansa é doutora em Educação pela Universidade Federal do Rio Grande do Sul (UFRGS). Licenciada em Filosofia pela Universidade Federal de Pelotas (UFPel). Pesquisadora da linha Arte, Linguagem e Currículo no Programa de Pós-graduação em Educação (PPGEDU) da UFRGS.

Rosa Maria Bueno Fischer é doutora em Educação pela Universidade Federal do Rio Grande do Sul (UFRGS). Pesquisadora do CNPq. Licenciada em Letras pela Universidade do Vale do Rio dos Sinos (UNISINOS). Pesquisadora da linha Arte, Linguagem e Currículo no Programa de Pósgraduação em Educação (PPGEDU) da UFRGS.

Recebido: 14 Ago 2019

Aceito: 04 Nov 2019 